\title{
ANALYSIS OF SELECTED DYNAMIC FEATURES OF A TWO-WHEELED TRANSMISSION SYSTEM
}

\author{
Piotr KRAWieC \\ Poznań University of Technology, Chair of Basics of Machine Design, Poznań, Poland \\ e-mail: piotr.krawiec@put.poznan.pl
}

\begin{abstract}
The paper presents results of analysis of selected dynamic features of an uneven-running two-wheeled strand transmission. The characteristic features of such type of transmissions is the ability of obtaining variable kinematic and dynamic features by the application of wheels with a noncircular envelope. Particularly, high interest of application of uneven-running transmissions was done in the previous century. At that time, a concept of application of such transmissions for process and machine control was invented. The applications in textile and engineering industry are widely known. A mathematical model of the multiplying transmission is presented. Few versions of dynamic features of the transmission for different loads and solid moments of inertia are examined. The presented results can be very helpful for designers of classical and uneven-running strand transmissions.
\end{abstract}

Keywords; transmission, variable gear ratio, mathematical model

\section{Introduction}

The analysis of dynamic features of a strand transmission with variable gear ratio is a complex and a nontypical process. This complexity results from the specific character of such a transmission, which is determined by the shape of the toothed wheel. It is found that there is a lack of scientific literature concerning empirical research of strand transmissions with noncircular toothed wheels.

The author of the work (Grzelak, 2007) presented the equation of motion of a strand transmission with elliptical wheels. He also estimated the influence of initial orientation and the geometry of rotating elements on the characteristics of velocity and acceleration, which are caused by an impulse of moment that is acting on the driving wheel. This problem was solved with the application of Matlab software. The author showed that the elliptical transmission with identical wheels can work as a transmission with a constant or periodically variable gear ratio. However, during the analysis of kinematics and dynamics, he did not take into account the following condition: length of the wrap of the transmission for any angle of rotation of the wheel must be a constant value and must be equal to length of the standard belt.

The subject of the work by Buśkiewicz (2000) was analysis of torque transfer in the transmission with one elliptical wheel and one circular wheel, which was eccentric fixed. The constant length of wrap was not kept in that transmission. The relationships between torques on driving and driven wheels were formulated for the analysed transmission.

The study by Kelm (2006) was about the determination of differences between lengths of driving and driven strands of the uneven-running two-wheeled transmission. The author presented the application of a pulley with a slight out-of-round in the drive of the timing gear of a combustion engine. He showed the advantages of such a solution in comparison with a classical strand transmission with circular wheels.

In the available literature, there is a lack of discussion about strand vibrations in unevenrunning transmissions. The studies concerning classical strand transmissions are only known 
(Kido et al., 1994; Krasiński and Stachoń, 1997, 2004; Martins and Robson, 2013). These studies do not exhaust the topic with reference to theory of vibrations (Bajkowski, 1989; Kurnik, 1985). However, one can find many publications about the load capacity of transmissions with different types of belts (Bulushi et al., 2015; Chen et al., 1998; Jang et al., 2014; Johannesson and Distner, 2002; Korolev, 1990).

The main purpose of the application of an uneven-running transmission is not transfer of power, but the obtaining of variable kinematic features. Therefore, forces resulting from continuous accelerating or decelerating of masses of noncircular belt pulleys have the essential influence on the load capacity of the transmission (without external resistant torque). The goal of the research is the determination of the influence of:

- mass moments of inertia of toothed wheels,

- values of coefficients of viscous damping,

- angular velocities of the driving shaft,

- resistant torques $M_{O P}$,

- load torques $M_{S}$

on the selected dynamic features of the uneven-running transmission.

Multiplying and reduction gear are taken into account in the research.

\section{The mathematical model of an uneven-running transmission}

Multiplying gear are taken into account in the presented research of transmissions.

Lagrange's equations of the 2nd type are basic equations for the determination of the equation of motion for the uneven-running transmission. The classical form of the equation is as follows

$$
\frac{d}{d t}\left(\frac{\partial E_{K}}{\partial \dot{u}_{i}}\right)-\frac{\partial E_{K}}{\partial u_{i}}+\frac{\partial E_{P}}{\partial u_{i}}+\frac{\partial R_{R}}{\partial \dot{u}_{i}}=F_{i} \quad i=1,2, \ldots, n
$$

where $E_{K}, E_{P}, E_{R}$ are kinetic, potential and dissipation energy of the system, respectively, $\dot{u}, u$ - velocities and generalized coordinates, $F_{i}$ - generalized excitation.

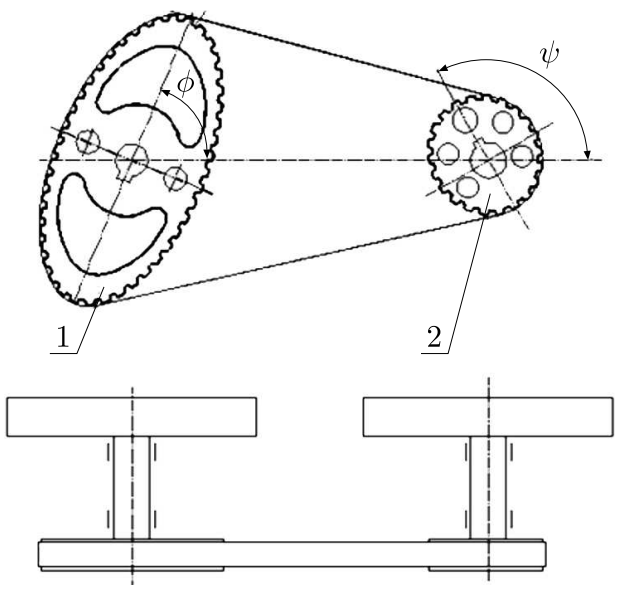

Fig. 1. A diagram of the strand transmission with noncircular cogbelt pulleys

In the analysed transmission

$$
E_{K}=\frac{1}{2} J_{1} \dot{\varphi}^{2}+\frac{1}{2} J_{2} \dot{\psi}^{2} \quad E_{R}=\frac{1}{2} C_{1} \dot{\varphi}^{2}+\frac{1}{2} C_{2} \dot{\psi}^{2}
$$

and $E_{P}=0$ - assumption: the strand is inextensible. 
After determining components of the energy and substituting these components to equation (2.1), the following form of the equation of motion for the strand transmission - multiplying gear (Fig. 1) has been obtained

$$
J_{1} \ddot{\varphi}+J_{2} \ddot{\varphi} \frac{\partial \psi}{\partial \varphi}+J_{2} \psi \frac{d}{d t} \frac{\partial \psi}{\partial \varphi}+C_{1} \dot{\varphi}+C_{2} \dot{\psi} \frac{\partial \psi}{\partial \varphi}=M_{S}-M_{O P} \frac{\partial \psi}{\partial \varphi}
$$

where $J_{1}, J_{2}$ are reduced mass moments of inertia for the driving and driven wheels and shafts, respectively, $\varphi$ - angle of rotation of the driving wheel, $\psi$ - angle of rotation of the driven wheel, $C_{1}, C_{2}$ - coefficients of viscous damping in the bearings of driving and driven shafts, $M_{S}$ - load torque of the driving wheel, $M_{O P}$ - resistance torque.

It is assumed that the transmission will be loaded with a constant resistance torque which is defined as

$$
M_{O P}=M_{O P \max }\left(1-\mathrm{e}^{-\alpha \dot{\varphi}}\right)
$$

In order to solve equation (2.2), one should determine the relationship $\psi=f(\varphi)$, which describes the change of the angle of rotation of the driven wheel in function of the angle of rotation of the driving wheel. The mean square trigonometric polynomial of the 6th degree is used for description of this relationship

$$
\psi=a \varphi+b \sin (2 \varphi)+c \sin (2 \varphi)+d \cos (4 \varphi)+e \sin (4 \varphi)+f \cos (6 \varphi)+\ldots+g(6 \varphi)
$$

The time derivative of the angle of rotation of the driven wheel (velocity) is determined as

$$
\begin{aligned}
\dot{\psi}= & \frac{d \psi}{d t}=a \dot{\varphi}-2 b \sin (2 \varphi) \dot{\varphi}+2 c \cos (2 \varphi) \dot{\varphi}-4 d \sin (4 \varphi) \dot{\varphi} \\
& +\ldots+4 e \cos (4 \varphi) \dot{\varphi}-6 f \sin (6 \varphi) \dot{\varphi}-6 g \cos (6 \varphi) \dot{\varphi}=\dot{\varphi} \frac{\partial \psi}{\partial \varphi}
\end{aligned}
$$

that is

$$
\dot{\psi}=\dot{\varphi} \frac{d \psi}{d t}
$$

The second time derivative of the angle of rotation of the driven wheel is determined as follows (acceleration)

$$
\begin{aligned}
\ddot{\psi}= & \frac{d \dot{\psi}}{d t}=a \ddot{\varphi}-2 b 2 \cos (2 \varphi) \dot{\varphi}^{2}-2 b \sin (2 \varphi) \ddot{\varphi}-2 \cdot 2 c \sin (2 \varphi) \dot{\varphi}^{2} \\
& +\ldots+2 c \cos (2 \varphi) \ddot{\varphi}-4 \cdot 4 d \cos (4 \varphi) \dot{\varphi}^{2}-4 d \sin (4 \varphi) \ddot{\varphi}-4 \cdot 4 d \cos (4 \varphi) \dot{\varphi}^{2} \\
& -\ldots-4 e \cos (4 \varphi) \ddot{\varphi}-6 \cdot 6 f \cos (6 \varphi) \dot{\varphi}^{2}-6 f \sin (6 \varphi) \varphi-6 \cdot 6 g \sin (6 \varphi) \dot{\varphi}^{2}+6 g \cos (6 \varphi) \ddot{\varphi}
\end{aligned}
$$

For simplification of the record, the following denotation is taken into consideration: $d \psi / d \varphi=C_{M}$, where the index $M$ denotes the multiplying gear

$$
\frac{d \psi}{d \varphi}=a-2 b \sin (2 \varphi)+2 c \cos (2 \varphi)-4 d \sin (4 \varphi)+4 e \cos (4 \varphi)-6 f \sin (6 \varphi)-\ldots-6 g \cos (6 \varphi)=C_{M}
$$

while

$$
\begin{aligned}
& \frac{d^{2} \dot{\psi}}{d \dot{\varphi}^{2}}=\frac{d}{d \varphi}\left(\frac{d \psi}{d \varphi}\right)=-4 b \cos (2 \varphi)-4 c \sin (2 \varphi)-16 d \cos (4 \varphi)-16 e \sin (4 \varphi) \\
& \quad-\ldots-36 f \cos (6 \varphi)-36 g \sin (6 \varphi)=-B_{M}
\end{aligned}
$$


The following relationship is determined as the last one

$$
\begin{aligned}
& \frac{d}{d t}\left(\frac{d \dot{\psi}}{d \dot{\varphi}}\right)=-4 b \cos (2 \varphi) \dot{\varphi}-4 c \sin (2 \varphi) \dot{\varphi}-16 d \cos (4 \varphi) \dot{\varphi}-16 e \sin (4 \varphi) \dot{\varphi} \\
& \quad-\ldots-36 f \cos (6 \varphi) \varphi-36 g \sin (6 \varphi) \dot{\varphi}
\end{aligned}
$$

For simplification of the record, the following denotation is taken into consideration:

$$
\begin{aligned}
& B_{M} \dot{\varphi}=4 b \cos (2 \varphi) \dot{\varphi}+4 c \sin (2 \varphi) \dot{\varphi}+16 d \cos (4 \varphi) \dot{\varphi}+16 e \sin (4 \varphi) \dot{\varphi} \\
& \quad+\ldots+36 f \cos (6 \varphi) \dot{\varphi}+36 g \sin (6 \varphi) \dot{\varphi}
\end{aligned}
$$

On the basis of relationships (2.4)-(2.7) and proper substitutions, the following form of equation (2.2) is obtained for the multiplying gear

$$
J_{1} \ddot{\varphi}+J_{2} \ddot{\varphi}\left(\frac{\partial \psi}{\partial \varphi}\right)^{2}-C_{M}^{2}-J_{2} \dot{\varphi}^{2} C_{M} B_{M} \dot{\varphi}+C_{1} \dot{\varphi}+C_{2} \dot{\varphi}\left(C_{M}\right)^{2}=M_{S}-M_{O P} C_{M}
$$

and finally

$$
\ddot{\varphi}=\frac{\left(M_{S}+2 B_{M} C_{M} J_{2}\right) \dot{\varphi}^{2}-\left(C_{1}+C_{2} C_{M}^{2}\right) \dot{\varphi}}{J_{1}+J_{2} C_{M}^{2}}
$$

\section{Results of numerical calculations}

A few variants of the dynamics of the two-wheeled uneven-running transmission for different values of load and mass moments of inertia are analysed below. In order to improve calculations, computer program Uneven-running strand transmission - Dynamics, NPC-D has been designed. This program has been written in Visual Basic. The constant step of integration with the value of $0.001 \mathrm{~s}$ has been assumed in calculations. The task has been solved with the use of the Runge-Kutta method of the 4th order.

At first, the multiplying gear with constant values of the kinematic excitation $\left(\omega_{1}=40 \mathrm{rad} / \mathrm{s}\right)$ and with the following data: $J_{1}=0.06 \mathrm{~kg} \cdot \mathrm{m}^{2}, J_{2}=0.01 \mathrm{~kg} \cdot \mathrm{m}^{2}, C_{1}=0 \mathrm{~N} \cdot \mathrm{m} \cdot \mathrm{s}, C_{2}=0 \mathrm{~N} \cdot \mathrm{m} \cdot \mathrm{s}$, $M_{S}=0 \mathrm{~N} \cdot \mathrm{m}, M_{O P}=0 \mathrm{~N} \cdot \mathrm{m}$ (Figs. 2 and 3 ) has been analysed. In order to simplify description of the axis in graphs, the following denotations are taken into consideration: $\omega$ - angular velocity, $a$ - acceleration.

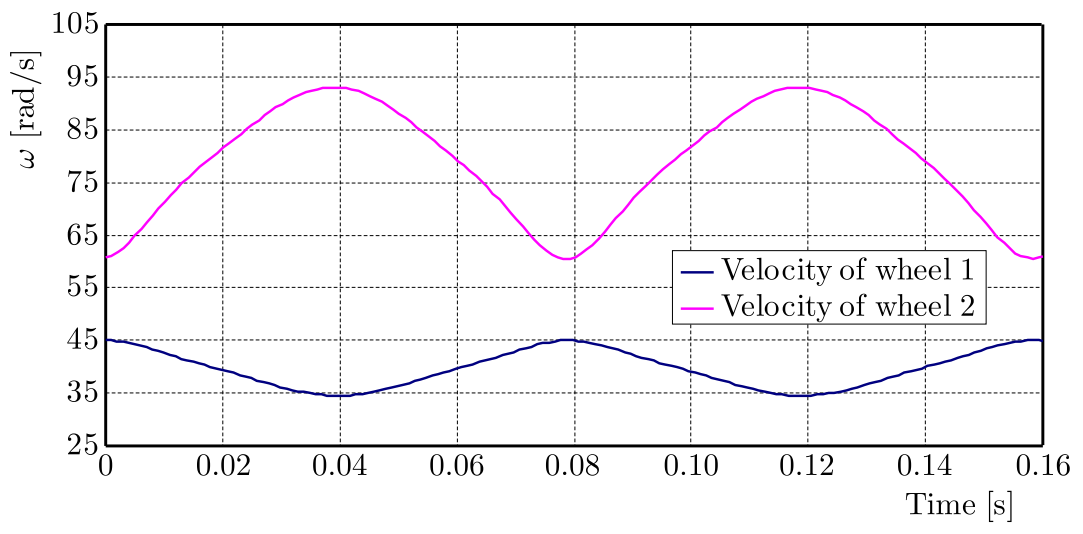

Fig. 2. Velocity of wheel 1 and 2 in function of time $\left(\omega_{1}=40 \mathrm{rad} / \mathrm{s}\right)$

Next figures (Figs. 4 and 5) present characteristics of velocity and acceleration of the gear wheels of the multiplying gear with the following values: $\omega_{1}=1 \mathrm{rad} / \mathrm{s}, J_{1}=0.06 \mathrm{~kg} \cdot \mathrm{m}^{2}$, $J_{2}=0.01 \mathrm{~kg} \cdot \mathrm{m}^{2}, C_{1}=0.002 \mathrm{~N} \cdot \mathrm{m} \cdot \mathrm{s}, C_{2}=0.01 \mathrm{~N} \cdot \mathrm{m} \cdot \mathrm{s}, M_{S}=0.1 \mathrm{~N} \cdot \mathrm{m}, M_{O P}=0 \mathrm{~N} \cdot \mathrm{m}$. 


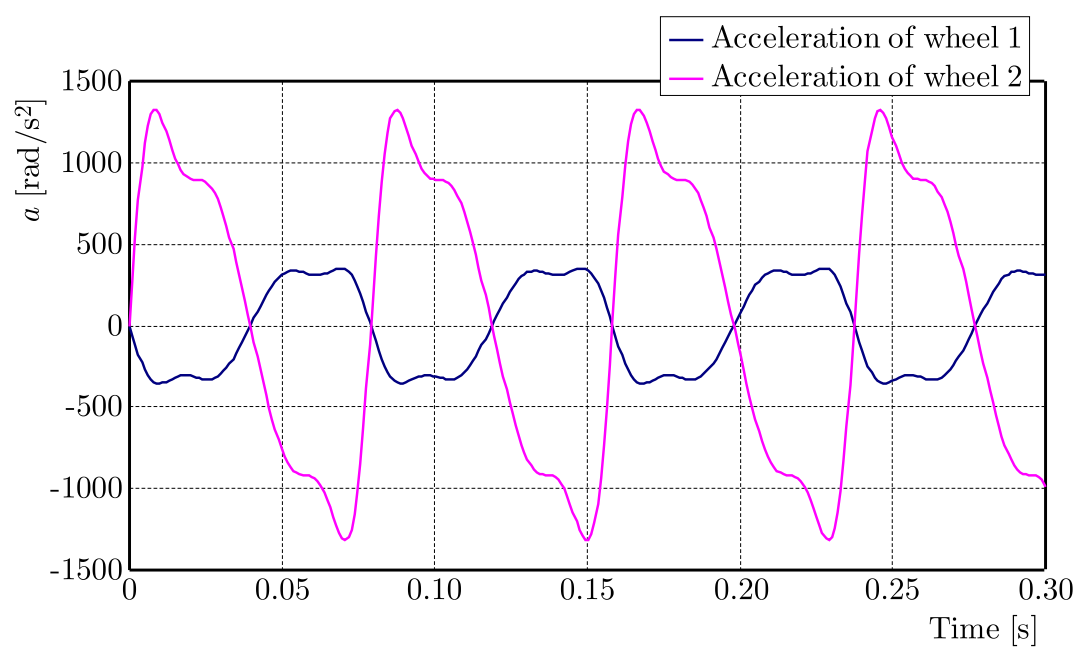

Fig. 3. Acceleration of wheel 1 and 2 in function of time $\left(\omega_{1}=40 \mathrm{rad} / \mathrm{s}\right)$

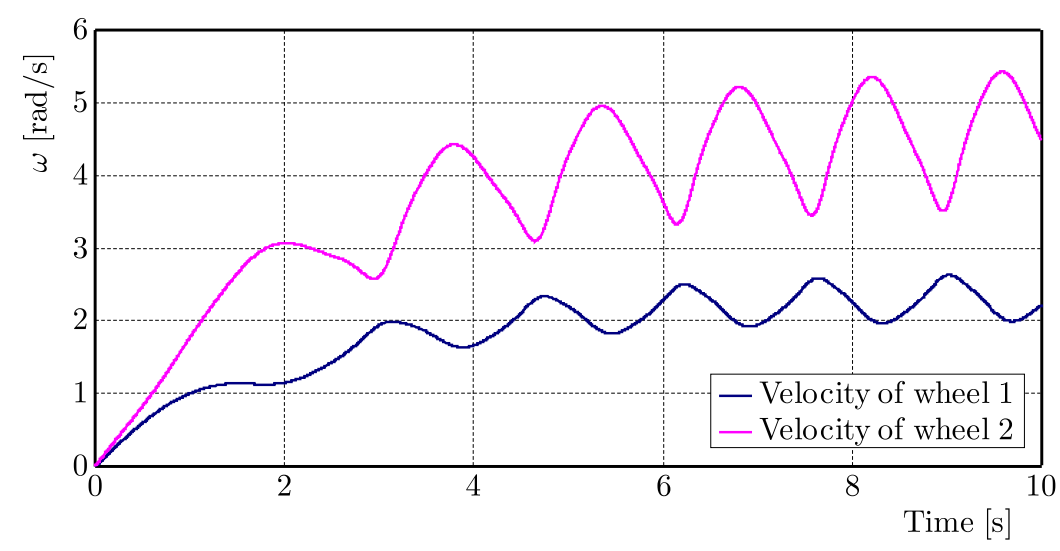

Fig. 4. Velocity of wheel 1 and 2 in function of time $\left(\omega_{1}=1 \mathrm{rad} / \mathrm{s}\right)$

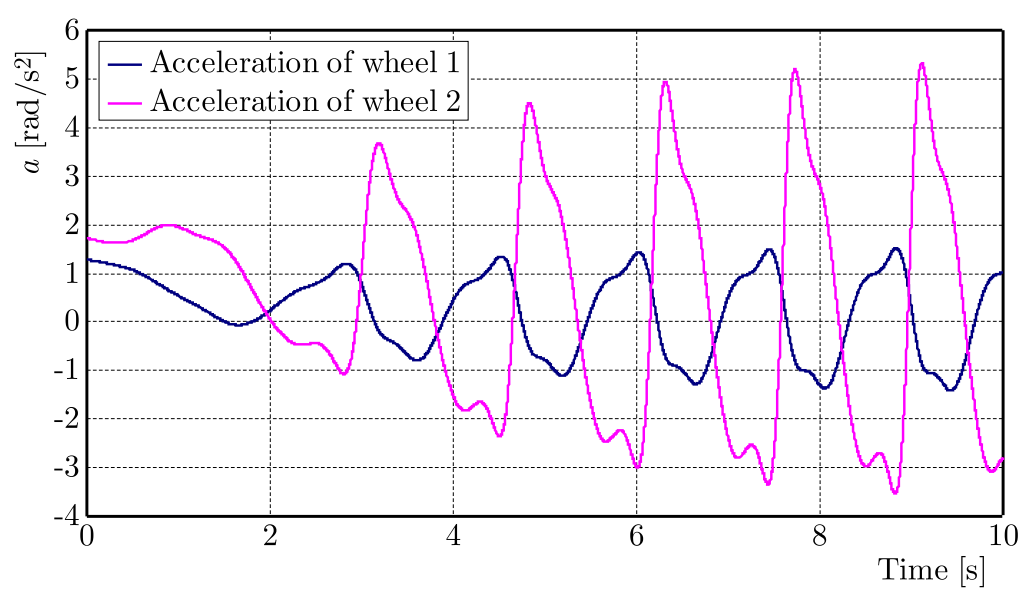

Fig. 5. Acceleration of wheel 1 and 2 in function of time $\left(\omega_{1}=1 \mathrm{rad} / \mathrm{s}\right)$

Figures 6 and 7 illustrate characteristics of the change in velocity and acceleration of the gear wheels of the multiplying gear for the following data: $J_{1}=0.3 \mathrm{~kg} \cdot \mathrm{m}^{2}, J_{2}=0.3 \mathrm{~kg} \cdot \mathrm{m}^{2}$, $C_{1}=0.02 \mathrm{~N} \cdot \mathrm{m} \cdot \mathrm{s}, C_{2}=0.02 \mathrm{~N} \cdot \mathrm{m} \cdot \mathrm{s}, M_{O P}=4 \mathrm{~N} \cdot \mathrm{m}, M_{S}=9 \mathrm{~N} \cdot \mathrm{m}$. 


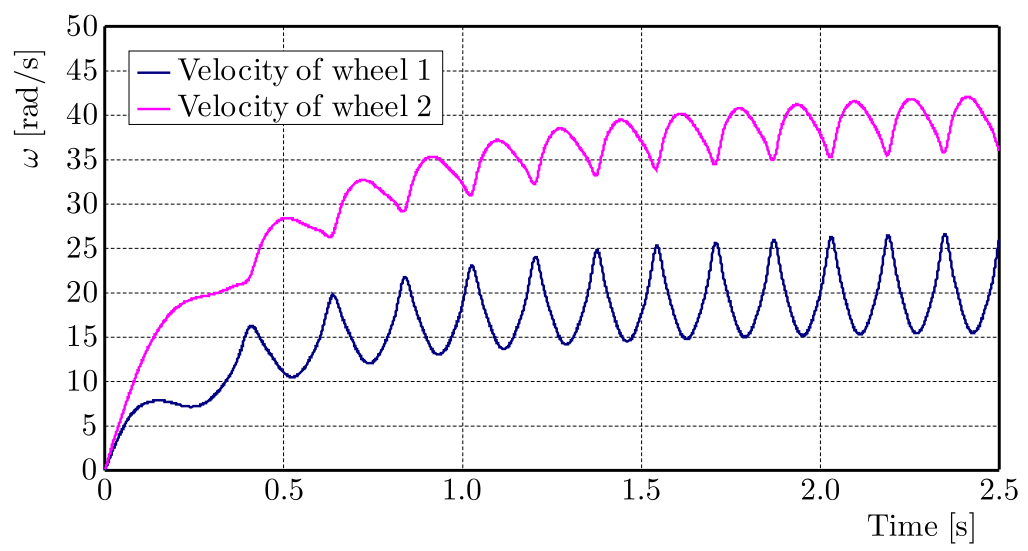

Fig. 6. Velocity of wheel 1 and 2 in function of time $\left(\omega_{1}=20 \mathrm{rad} / \mathrm{s}\right)$

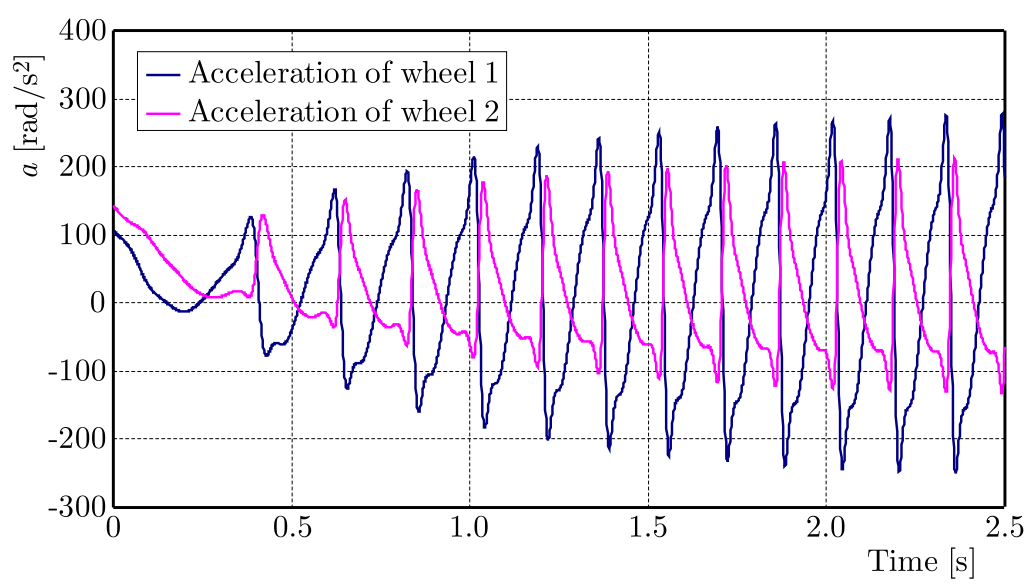

Fig. 7. Acceleration of wheel 1 and 2 in function of time $\left(\omega_{1}=20 \mathrm{rad} / \mathrm{s}\right)$

\section{Summary}

On the basis of the determined characteristics of the mathematical model of the transmission, one can draw the following conclusions and observations:

- Considerable accelerations of the driven wheels occur for low values of mass moments of inertia and for relatively high values of velocities.

- Constant gear ratio and constant accelerations can be obtained when the dimensions (mass) of the gear wheels are great.

- The transmission can not work with a too high rotational speed.

- In the case of multiplying gear with the following values of mass moments of inertia: $J_{1}=0.06 \mathrm{~kg} \cdot \mathrm{m}^{2}$ and $J_{2}=0.01 \mathrm{~kg} \cdot \mathrm{m}^{2}$, without the external load and on the assumption that frictional resistance is neglected; one can observe (during kinematic excitation) that the velocity of the driving wheel is characterized by considerable variability for a quasi-constant velocity of the driven wheel. In the range of velocity from $10 \mathrm{rad} / \mathrm{s}$ to $40 \mathrm{rad} / \mathrm{s}$, the acceleration of the driven wheel is 15 times higher than the acceleration of the driving wheel.

- For the multiplying gear with the considered conditions: viscosity friction, small torque $M_{S}$ and no resistance torque; the characteristics of rotational speed and acceleration are similar but their amplitudes are different, and the acceleration of wheel 1 is higher than the acceleration of wheel 2. 
- The resistance torque which is placed in the description of the analysed transmission, does not cause any changes to the characteristics of velocity and acceleration. However, in this case, the acceleration of the driven wheel is higher than the acceleration of the driving wheel.

- Equal and relatively small values of mass moments of inertia for both wheels and the following assumptions: no frictional resistance and no loads; lead to higher amplitudes of velocity and acceleration in comparison with transmissions with different mass moments of inertia.

\section{References}

1. Bajkowski J., 1989, Theorie des vibrations, Oran, Office des Publications Universitaires

2. Bulushi A., Rameshkumar G.R., Lokesha M., 2015, Fault diagnosis in belts using time and frequency based signal processing techniques, International Journal of Multidisciplinary Sciences and Engineering, 6, 11, 12-20

3. Buśkiewicz J., 2000, Non-uniform torque transmitted by a non-circular belt gear, Machine Dynamics Problems, 24, 3, 11-18

4. Chen T.F., Lee D.W., Sung C.K., 1998, An experimental study on transmission efficiency of a rubber V-belt CVT, Mechanisms and Machine Theory, 33, 4, 351-363

5. Grzelak M., 2007, Impulse characteristics of strand transmission with elliptical rotors (in Polish), XXIII Sympozjon Podstaw Konstrukcji Maszyn, Rzeszów-Przemyśl, 225-233

6. Jang J.J.I., Kwon O.E., Chai M.J., Kim H.S., 2014, Power transmission dynamics in micro and macro slip regions for a metal v-belt continuously variable transmission under external vibrations, International Journal of Automotive Technology, 15, 7, 1119-1128

7. Johannesson T., Distner M., 2002, Dynamic loading of synchronous belts, Journal of Mechanical Design, 124, 3, 79-85

8. Kelm P., 2006, Dynamiksimulation von Zahnriemengetrieben mit ungleichformiger Übersetzung, Dresden, Tagung Zahnriemengetriebe TU, 56-64

9. Kido R., Kussano T., FujII T., 1994, A new approach for analyzing load distribution of toothed belts at steady states using FEM, SAE Society of Automotive Engineers Technical Paper Series 940690, 1234-1243

10. Korolev N., 1990, Zugkraftverlauf und Belastungsverteilung in Zahnriemenantrieben, Konstruktion, 42, 47-253

11. Krasiński M., Stachoń S., 1997, Analysis of dynamics of strand transmissions with vee-belts and cogbelts (in Polish), XVIII Sympozjon Podstaw Konstrukcji Maszyn, Kielce Ameliówka, 177-182

12. Krasiński M., Stachoń S., 2004, Investigations of dynamics of strand transmission with cogbelts (in Polish), Czasopismo Techniczne, 13, 63-73

13. Kurnik W., 1985, Theory of Vibrations - Casebook (in Polish), Wydawnictwo Politechniki Warszawskiej, Warszawa

14. Martins D.R., Robson P., 2013, Nonlinear model of belt-tensioner system with experimental validation, 11th International Conference on Vibration Problems, Lisbon, 1-10 